\title{
Three-layer microfibrous peripheral nerve guide conduit composed of elastin-laminin mimetic artificial protein and $\operatorname{poly}($ L-lactic acid)
}

\author{
Sachiro Kakinoki ${ }^{1}$, Midori Nakayama ${ }^{1,2}$, Toshiyuki Moritan' ${ }^{2}$ and Tetsuji Yamaoka ${ }^{1 *}$ \\ 1 Department of Biomedical Engineering, National Cerebral and Cardiovascular Center Research Institute, Suita, Japan \\ ${ }^{2}$ Department of Clinical Engineering, Faculty of Medical Engineering, Suzuka University of Medical Science, Suzuka, Japan
}

Edited by:

Carissa M. Soto, Naval Research

Laboratory, USA

Reviewed by:

Henrique De Amorim Almeida,

Polytechnic Institute of Leiria,

Portugal

Hongyan Sun, City University of

Hong Kong, Hong Kong

*Correspondence:

Tetsuji Yamaoka, Department of Biomedical Engineering, National

Cerebral and Cardiovascular Center Research Institute, 5-7-1 Fujishirodai, Suita, Osaka 565-8565, Japan

e-mail: yamtet@ncvc.go.jp
We developed a microfibrous poly(L-lactic acid) (PLLA) nerve conduit with a three-layered structure to simultaneously enhance nerve regeneration and prevent adhesion of surrounding tissue. The inner layer was composed of PLLA microfiber containing $25 \%$ elastin-laminin mimetic protein ( $\mathrm{AG} 73-(\mathrm{VPGIG})_{30}$ ) that promotes neurite outgrowth. The thickest middle layer was constructed of pure PLLA microfibers that impart the large mechanical strength to the conduit. A 10\% poly(ethylene glycol) was added to the outer layer to prevent the adhesion with the surrounding tissue. The AG73-(VPGIG) 30 compositing of an elastin-like repetitive sequence (VPGIG) 30 and a laminin-derived sequence (RKRLQVQLSIRT: AG73) was biosynthesized using Escherichia coli. The PLLA microfibrous conduits were fabricated using an electrospinning procedure. AG73-(VPGIG) 30 was successfully mixed in the PLLA microfibers, and the PLLA/AG73-(VPGIG) 30 microfibers were stable under physiological conditions. The PLLA/AG73-(VPGIG) 30 microfibers enhanced adhesion and neurite outgrowth of PC12 cells. The electrospun microfibrous conduit with a three-layered structure was implanted for bridging a $2.0-\mathrm{cm}$ gap in the tibial nerve of a rabbit. Two months after implantation, no adhesion of surrounding tissue was observed, and the action potential was slightly improved in the nerve conduit with the PLLA/AG73-(VPGIG) 30 inner layer.

Keywords: poly(L-lactic acid), elastin-laminin mimetic protein, electrospun microfiber, nerve conduit, tissue adhesion prevention

\section{INTRODUCTION}

Traumatic nerve injuries in which direct suturing of the proximal and distal stumps is difficult due to the long nerve gap are generally treated with nerve autografts. However, autologous nerve grafting has several disadvantages, such as size mismatch and permanent loss of donor function due to the extraction of normal nerve. As an alternative, artificial nerve conduits have become widely accepted for bridging gaps between nerve stumps (Ichihara et al., 2008; Lohmeyer et al., 2009; Sieminow and Brzezicki, 2009).

Artificial nerve conduits constructed of numerous polymeric materials such as silicone (Lundborg et al., 1982), collagen (Archibald et al., 1995), chitosan (Freier et al., 2005; Ao et al., 2006), hyaluronic acid (Wang et al., 1998), poly(caprolactone) (PCL), poly(glycolic acid) (PGA), and poly(lactic acid) (PLA) (Nakamura et al., 2004; Yoshitani et al., 2007) have been investigated. Recently, an artificial nerve conduit composed of poly(lactic-co-glycolic acid) (PLGA) mesh filled with animalderived collagen has been put into clinical use and has shown good performance (Nakamura et al., 2004). PLGA is hydrolyzed and metabolized in vivo, and thus the PLGA conduit is absorbed during nerve regeneration over the course of several months (Mainil-Varlet et al., 1996). Because PLGA does not possess any biological activity, collagen is used for promoting nerve regeneration. Collagen is a major component of the basement membrane of nerve tissue and plays a key role in the reconstruction of the axon network by Schwann cells (Thomas, 1964; Chernousov et al., 2008). Although collagen strongly enhances nerve regeneration, animal-derived materials raise concerns about viral infection and immune responses (Lynn et al., 2004). The mesh structure of this conduit is effective for inhibiting the intrusion of surrounding connective tissues and for allowing the permeation of liquid factors and small molecules. However, the mesh structure promotes adherence with surrounding tissues and can cause painful traction neuropathies (Smit et al., 2004). Hence, the ideal conduits for promoting nerve regeneration and preventing tissue adhesion would not include animal-derived materials.

To avoid the use of animal-derived materials, short peptide sequences isolated from extracellular matrix proteins can be used, because they show biological activity equal to that of full-length proteins. For example, the RGD sequence of fibronectin provides excellent cell adhesive properties (Hersel et al., 2003). Focusing on nerve regeneration, the IKVAV (Tashiro et al., 1989), YIGSR (Iwamoto et al., 1987), and RKRLQVQLSIRT (AG73) (Nomizu et al., 1996) sequences derived from laminin have been well studied in the activation of neural cells. These small peptides are 
easily synthesized chemically or biologically and are useful for imparting nerve regenerative activity to polymeric materials (Rao and Winter, 2009; Kakinoki and Yamaoka, 2010). Suzuki et al. prepared IKVAV- or YIGSR-immobilized tendon chitosan tubes and demonstrated the efficacy of peptide immobilization for assisting nerve regeneration in a rat model of nerve injury (Suzuki et al., 2003a). Previously, we reported that poly(L-lactic acid) (PLLA) nerve conduits modified with laminin-derived AG73 peptides and a polyethylene glycol (PEG)-containing outer layer are effective for preventing the adhesion of surrounding tissue (Kakinoki et al., 2011). The AG73 peptide was immobilized onto PLLA microfibers using oligo(D-lactic acid) (ODLA)-AG73 conjugates. The microfibers were fabricated by electrospinning of a mixed solution containing PLLA and the ODLA-AG73 conjugate, resulting in stable immobilization of the AG73 peptide via stereocomplex formation between the PLLA and the ODLA. Regeneration of functional nerve tissue was observed in AG73immobilized microfibrous nerve conduit in the rat model of nerve injury, but it required a long period of time, approximately 6 months. Thus, the efficiency of AG73-immobilized microfibers is insufficient for nerve regeneration. We speculated that the efficacy of AG73 immobilization was decreased immediately after implantation by release of the low-molecular weight PDLA-AG73 conjugates from the microfibers in vivo.

To fabricate a more effective biological material for nerve regeneration, we designed and biosynthesized a high molecular weight elastin-laminin mimetic protein. The basement membrane of nerve tissue is primarily constructed with collagen, laminin, and elastin (Rutka et al., 1988). These proteins cooperatively support the process of nerve regeneration. Specifically, collagen and laminin function in axon extension, and elastin provides elasticity for the tissue structure (Toyota et al., 1990). We previously biosynthesized an elastinlaminin mimetic protein and used it for the functionalization of PLLA scaffolds (Kakinoki and Yamaoka, 2014). This protein is composed of 30 repeats of an elastin-like VPGIG repetitive sequence and a laminin-derived AG73 sequence (AG73(VPGIG) ${ }_{30}$ ). AG73-(VPGIG) 30 showed temperature-dependent coacervation in phosphate buffered saline (PBS) solution at approximately $14^{\circ} \mathrm{C}$. Because the AG73-(VPGIG) 30 was insoluble at body temperature, this protein was expected to serve as a suitable scaffold for nerve regeneration. Our results showed that the adhesion and neurite outgrowth of PC12 cells were enhanced on the AG73-(VPGIG) 30 adsorbed PLLA films in vitro.

In this study, we prepared PLLA microfibrous nerve conduit with a three-layered structure that promoted nerve regeneration and prevented tissue adhesion. The therapeutic efficacy of peripheral nerve regeneration was evaluated using a rabbit model of nerve injury. Microfibrous conduits composed of a PLLA, PLLA/AG73, or PLLA/AG73-(VPGIG) 30 inner layer, a PLLA middle layer, and a PLLA/PEG outer layer were fabricated using an electrospinning procedure. Adhesion and neurite outgrowth of PC12 cells on PLLA microfibers containing AG73-(VPGIG) 30 were studied in vitro. Nerve autografts and microfibrous conduits were implanted in rabbits to bridge a $2-\mathrm{cm}$ tibial nerve gap. Two months after implantation, nerve regeneration was evaluated by electrophysiological measurements.

\section{MATERIALS AND METHODS EXPRESSION AND PURIFICATION OF THE ELASTIN-LAMININ MIMETIC PROTEIN}

The elastin-laminin mimetic protein (AG73-(VPGIG) $)_{30}$ ) was expressed by Escherichia coli BL21(DE3)pLysS (Life Technologies Corporation, Carlsbad, CA, USA) that had been transformed with the pET28 $(+)$ vector (Merck KGaA, Darmstadt, Germany) encoding AG73-(VPGIG) 30 , as described previously (Kakinoki and Yamaoka, 2014). AG73-(VPGIG) 30 expression was automatically induced using an Overnight Express ${ }^{\mathrm{TM}}$ Autoinduction System (Merck KGaA). Briefly, E. coli cells were incubated in $2 \times$ YT medium supplemented with $34 \mu \mathrm{g} / \mathrm{mL}$ of kanamycin and the reagents of the Overnight Express ${ }^{\mathrm{TM}}$ Autoinduction System at $30^{\circ} \mathrm{C}$ for $24 \mathrm{~h}$. E. coli was harvested by centrifugation at $3500 \times g$ at $4^{\circ} \mathrm{C}$ for $15 \mathrm{~min}$. Bacterial pellets were resuspended in lysis solution $\left(8 \mathrm{M}\right.$ urea) and frozen at $-80^{\circ} \mathrm{C}$. After thawing, bacteria were disrupted by sonication on ice. Insoluble debris was removed by centrifugation at $10,000 \times g$ at $4^{\circ} \mathrm{C}$ for $15 \mathrm{~min}$, and the supernatant was purified on a His-tag affinity column (COSMOGEL His-Accept, Nacalai Tesque, Kyoto, Japan).

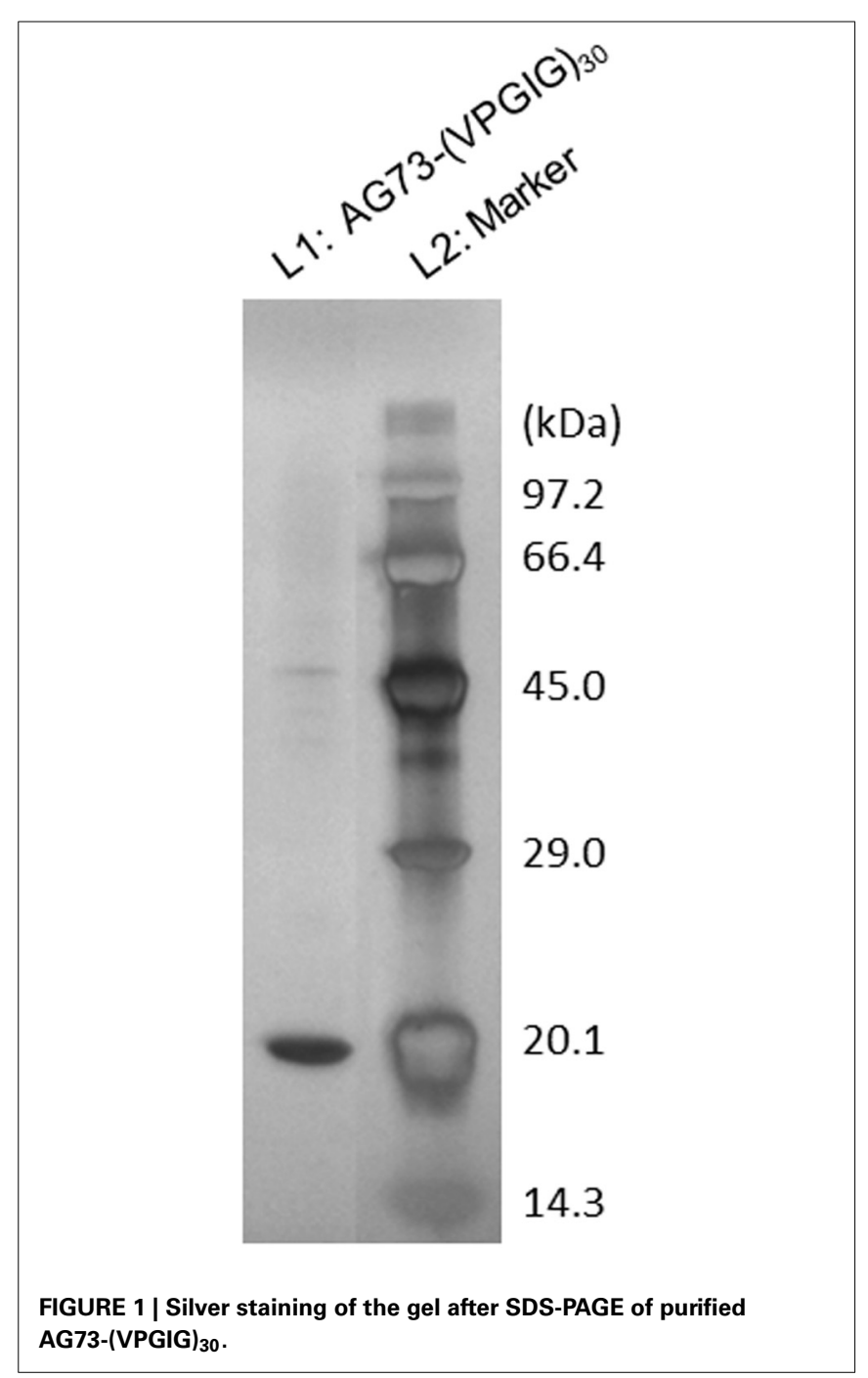


Following dialysis $(\mathrm{MwCo}=10,000 \mathrm{Da})$ in deionized water at $4^{\circ} \mathrm{C}$, purified AG73-(VPGIG) 30 was obtained by lyophilization. The purity of the AG73-(VPGIG) 30 was confirmed by sodium dodecyl sulfate-polyacrylamide gel electrophoresis (SDS-PAGE) analysis with silver staining.

\section{FABRICATION OF PLLA/AG73-(VPGIG) 30 NON-WOVEN MICROFIBERS}

A PLLA/AG73-(VPGIG) 30 solution with a concentration of 20w\% was prepared by dissolving PLLA (Mw: 106,000, Mn: 60,000, Mw/Mn: 1.77) (Musashino Chemical Laboratory, Inc., Tokyo, Japan) and AG73-(VPGIG) 30 in hexafluoroisopropanol (HFIP) at a weight ratio of $4: 1$. This solution was electrospun using a plastic syringe equipped with a stainless steel needle (length $=15.0 \mathrm{~mm}$, diameter $=20 \mathrm{G}$ ) at a constant feed rate of $4 \mathrm{~mL} / \mathrm{h}$. An aluminum plate was used as a target and the distance between the target and the needle tip was $100 \mathrm{~mm}$. The solution was electrospun at a high voltage $(15 \mathrm{kV})$ for $5 \mathrm{~min}$. Non-woven PLLA/AG73-(VPGIG) 30 microfibers were collected and cut for subsequent experiments. Non-woven PLLA and PLLA/AG73 microfibers were prepared using a similar procedure. The concentration of the AG73 peptide (Purity $>82.6 \%$; SigmaAldrich, Inc.) in the PLLA/AG73 solution was adjusted to the same molarity as that of the AG73-(VPGIG) 30 in the non-woven PLLA/AG73-(VPGIG) 30 microfibers. After immersion in PBS for $24 \mathrm{~h}$ at $37^{\circ} \mathrm{C}$, the structure of the non-woven microfibers was observed by scanning electron microscopy (SEM; JCM-5700, JEOL, Tokyo, Japan).

\section{NEURITE OUTGROWTH ASSAY}

A neurite outgrowth assay was performed using rat adrenal pheochromocytoma (PC12) cells (RIKEN BioResorce Center, Ibaraki, Japan), which are widely used as a model for neural stem cells. PC12 cells were maintained in Dulbecco's modified Eagles medium (DMEM) supplemented with 100 units/mL penicillin, $100 \mu \mathrm{g} / \mathrm{mL}$ streptomycin (Life Technologies Corporation, Carlsbad, CA, USA), 10\% fetal bovine serum (FBS; MP Biomedicals, Inc., Solon, OH, USA), and 7.5\% horse serum (HS; Sigma-Aldrich, Inc., St. Louis, MO, USA). PC12 cells were cultured in poly-D-lysine-coated cell culture dishes (Asahi Glass Co., Ltd., Tokyo, Japan) and maintained at $37^{\circ} \mathrm{C}$ in a $5 \% \mathrm{CO}_{2}$ atmosphere. Prior to the neurite growth assay, $\mathrm{PC} 12$ cells were cultivated in DMEM/F12 medium (Life Technologies Corporation, Carlsbad, CA, USA) with $100 \mathrm{ng} / \mathrm{mL}$ nerve growth factor (NGF; Sigma-Aldrich, Inc.) for $24 \mathrm{~h}$ on polystyrene cell culture dishes. The medium was refreshed with normal culture medium, and cells were incubated for $30 \mathrm{~min}$ at $37^{\circ} \mathrm{C}$ in a $5 \% \mathrm{CO}_{2}$ atmosphere. Cells were harvested by gentle agitation and resuspended in advanced DMEM/F12 containing 5 $\mathrm{mg} / \mathrm{mL}$ insulin (Life Technologies Corporation, Carlsbad, CA, USA), $100 \mathrm{ng} / \mathrm{mL}$ NGF, $20 \mathrm{nM}$ progesterone, $100 \mathrm{mg} / \mathrm{mL}$ transferrin, and $30 \mathrm{nM}$ sodium selenite $\left(\mathrm{Na}_{2} \mathrm{SeO}_{3}\right)$ (Nacalai Tesque, Inc., Kyoto, Japan), and seeded on non-woven microfibers fixed with Cell Crown (Scaffdex Ltd., Tampere, Finland) in 24well cell culture plates at a density of $2.0 \times 10^{4}$ cells/sample. After $48 \mathrm{~h}$ incubation at $37^{\circ} \mathrm{C}$ in a $5 \% \mathrm{CO}_{2}$ atmosphere,

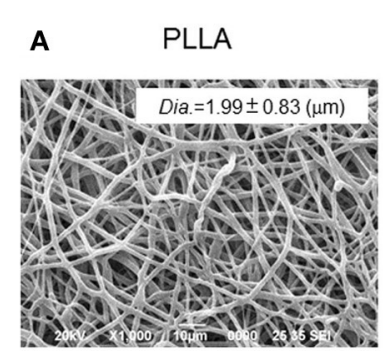

B
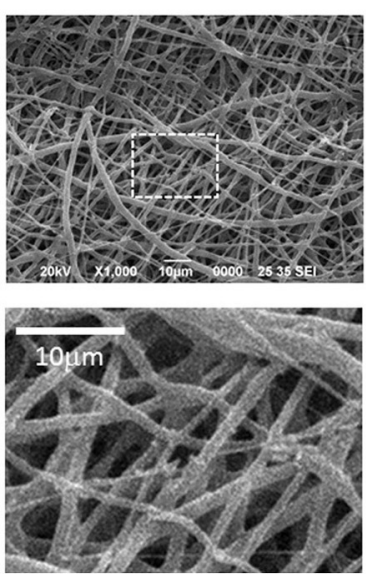

PLLA/AG73

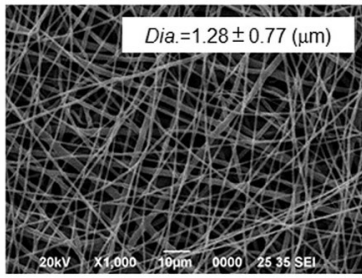

PLLA/AG73
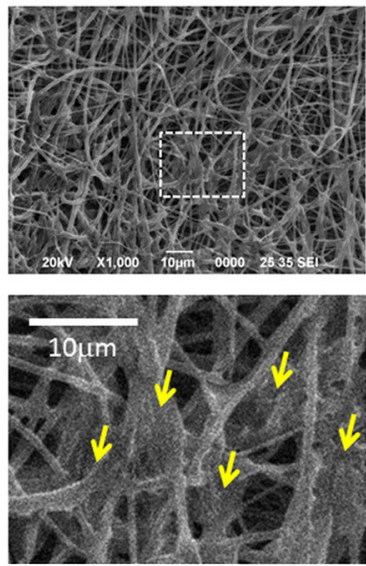

\section{PLLA/AG73-(VPGIG) 30}

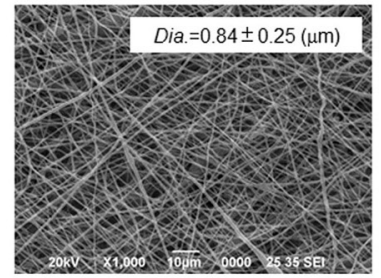

PLLA/AG73-(VPGIG) 30
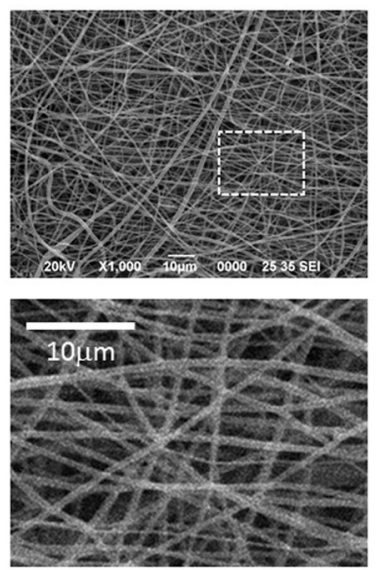

FIGURE 2 | SEM images of electrospun PLLA, PLLA/AG73, and PLLA/ AG73-(VPGIG) 30 micro-fibers (A) before and (B) after immersion in PBS for $24 \mathrm{~h}$ at $37^{\circ} \mathrm{C}$. Yellow arrows indicate fusion points. 
cells adherent to the non-woven fibers were fixed with $10 \%$ formalin and stained with $4 \%$ crystal violet/methanol solution. The number of adherent cells observed in the stained images were counted and categorized according to neurite length.

\section{FABRICATION OF PLLA/AG73-(VPGIG) 30 MICROFIBROUS CONDUIT}

We designed the electrospun microfibrous conduits with 3 layer structure, PLLA, PLLA/AG73, or PLLA/AG73-(VPGIG) 30 inner layer, PLLA middle layer, and PLLA/polyethylene glycol (PEG) outer layer. For fabricating conduits, a rotating stainless steel tube (outer diameter $=2.0 \mathrm{~mm}$, speed $=1500 \mathrm{rpm}$ ) was used as a target. Other conditions for electrospinning were completely same to nonwovens. First, inner layer (PLLA, PLLA/AG73, or PLLA/AG73-(VPGIG) 30 $_{30}$ ) was electrospun as described previously for $5 \mathrm{~min}$. Middle layer was electrospun with $20 \mathrm{w} \%$ of PLLA solution for $30 \mathrm{~min}$. Then, the mixed solution at $20 \mathrm{w} \%$ containing PLLA and PEG (9:1) was electrospun for $10 \mathrm{~min}$ as an outer layer. The matrices mass for inner, middle, and outer layer were adjusted to 1: 6: 2 for covering inner and outer surface of the mechanically strong middle layer. Microfibrous conduits were cut to length of $22 \mathrm{~mm}$, and immersed in 70\%-ethanol for the sterilization. After drying in vacuo, conduits were used for animal experiment.

\section{IMPLANTATION OF MICROFIBROUS CONDUITS}

Electrospun microfibrous conduits were implanted into $2.0-\mathrm{cm}$ gaps in the left tibial nerve of a total of 12 New Zealand white rabbits (3.0-3.5 kg, male) (Oriental Yeast Co., Ltd., Tokyo, Japan). This study was performed in accordance with the animal experimental guidelines of the National Cerebral and Cardiovascular Center Research Institute. Rabbits were anesthetized by intramuscular injection of $0.1 \mathrm{~mL} / \mathrm{kg}$ of Selactar (Bayer Yakuhin, Ltd., Osaka, Japan) and anesthesia was maintained by inhalation of 3\% Escain isoflurane (Mylan Inc., Canonsburg, PA, USA). Under an operating microscope, the left tibial nerve was exposed and a 2.0 -cm segment was removed. A section of microfibrous conduit was filled with physiological saline solution and sutured with 10-0 vicryl (Ethicon, Somerville, NJ, USA) to bridge the gap between the proximal and distal stumps. Both nerve stumps were pulled $1.0 \mathrm{~mm}$ inside the conduits. In addition, the removed nerve tissue was inverted on its proximal-distal axis and implanted as an autograft control. Muscle and skin were closed with 3-0 silk sutures (Ethicon), and the rabbits were allowed to recover in a controlled environment.

\section{ELECTROPHYSIOLOGICAL ANALYSIS}

Two months after implantation, nerve regeneration was evaluated by electrophysiological analysis. Rabbits were anesthetized in the same manner as for transplantation of the microfibrous conduits, and the implanted site was exposed from the proximal to the distal portions. In order to record electromyograms at the implantation site, a pair of stimulating and recording electrodes was attached to the proximal and distal portions, respectively. Both electrodes were connected to an electric stimulator (SEN3401, Nihon Kohden, Tokyo, Japan) and a data acquisition system

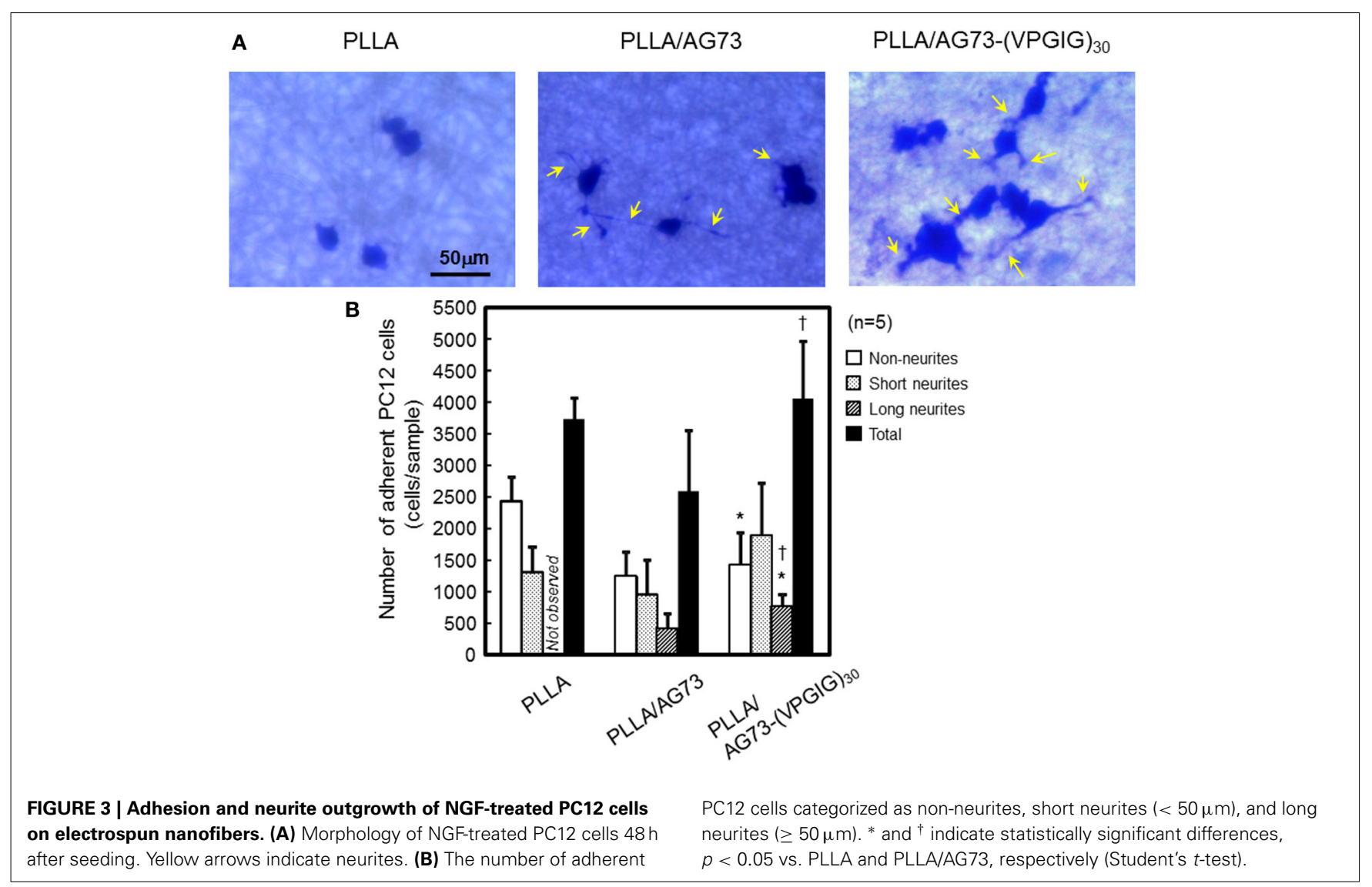


(PowerLab 8/30, ADInstruments, Colorado Springs, CO, USA). The stimulation parameters were as follows: strength $=1 \mathrm{~V}$, current $=1 \mathrm{~mA}$, duration $=10 \mathrm{~s}$, pulse width $=0.1 \mathrm{~ms}$. The active potential was amplified using a PowerLab system (ADInstruments, Burlingame, CA, USA), and recorded as the average of 50 traces.

\section{RESULTS AND DISCUSSION \\ EXPRESSION AND PURIFICATION OF ELASTIN-LAMININ MIMETIC PROTEIN}

SDS-PAGE analysis of purified AG73-(VPGIG) 30 is shown in Figure 1. A single band was observed at $17-18 \mathrm{kDa}$, which is concordant with the theoretical molecular weight. Sixty milligrams of high-purity AG73-(VPGIG) 30 was successfully obtained from $1 \mathrm{~L}$ of culture medium. As previously reported, PBS solution containing AG73-(VPGIG) 30 demonstrated temperature-dependent coacervation at $14^{\circ} \mathrm{C}$, indicating that the protein is insoluble at $37^{\circ} \mathrm{C}$ in a physiological environment (Kakinoki and Yamaoka, 2014).

\section{MORPHOLOGY AND STABILITY OF ELECTROSPUN NON-WOVEN MICROFIBERS}

SEM images of PLLA, PLLA/AG73, and PLLA/AG73-(VPGIG) 30 non-woven microfibers before and after PBS immersion are shown in Figure 2. The diameter of the PLLA microfibers was approximately $2.0 \mu \mathrm{m}$ (Figure 2A). When AG73 or AG73$(\text { VPGIG })_{30}$ was mixed with the PLLA, the diameter of the

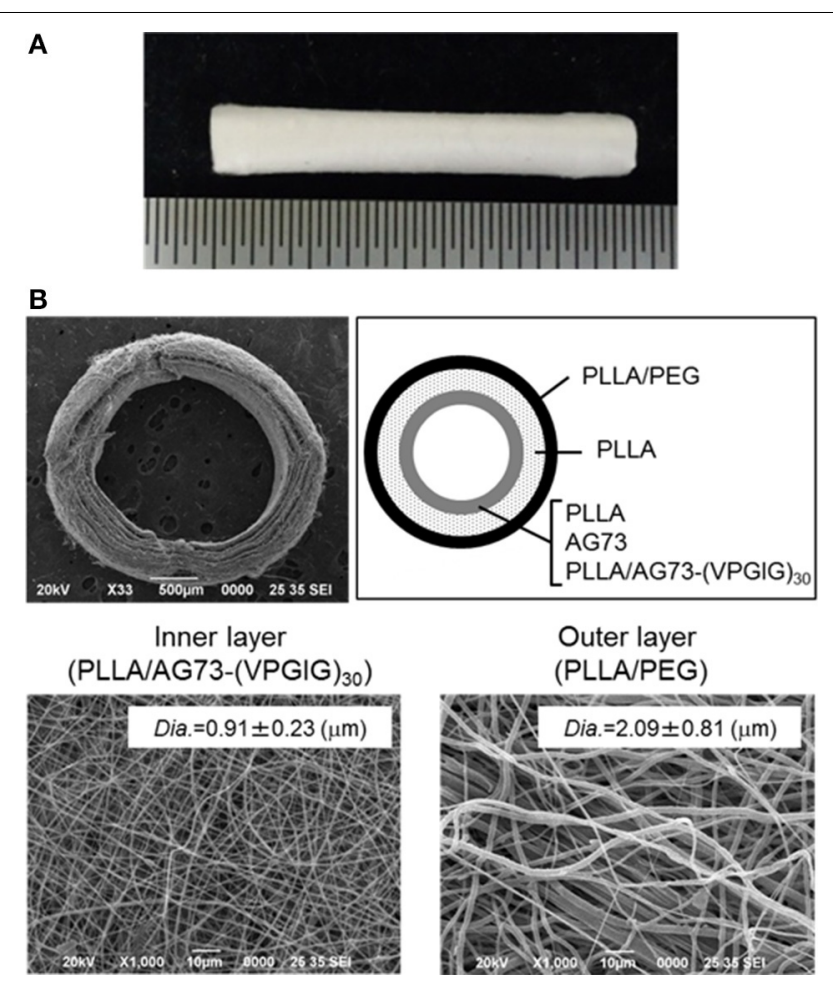

FIGURE 4 | Micro-fibrous nerve conduit with a three-layered structure. (A) Whole image, (B) SEM images of cross-sections and inner and outer layers. microfibers decreased to approximately 1.3 and $0.9 \mu \mathrm{m}$, respectively. The diameter of electrospun microfibers is known to be influenced by solution viscosity and electronic charge (Huang et al., 2003). The PLLA concentration was decreased by the addition of the AG73 and AG73-(VPGIG) 30 , thus decreasing the viscosity of the solution. Furthermore, the electronic charge of the solution should be positive because AG73 is positive due to its Arg and Lys residues. We assumed that the diameter of the microfibers was decreased by the changes in solution viscosity and electronic charge with the addition of the AG73 and AG73(VPGIG) 30 . The surfaces of the PLLA/AG73 and PLLA/AG73(VPGIG) 30 were smooth, without phase separation, suggesting that the AG73 and AG73-(VPGIG) 30 were homogeneously mixed.

The morphology of the microfibers following immersion in PBS for $24 \mathrm{~h}$ is shown in Figure 2B. The shape of the PLLA microfibers did not differ before and after immersion in PBS. However, the morphology of PLLA/AG73 microfibers became rough and some fusion appeared (Figure $2 \mathbf{B}$; indicated with yellow arrows) after PBS immersion. These morphological changes suggested that the PLLA/AG73 microfibers partially dissolved in PBS. In contrast, the morphology of PLLA/AG73-(VPGIG) 30 microfibers did not change after PBS immersion, indicating that the PLLA/AG73-(VPGIG) 30 microfibers were stable in a physiological environment.

\section{NEURITE OUTGROWTH OF PC12 CELLS ON NON-WOVEN MICROFIBERS}

The morphology and number of PC12 cells adherent on nonwoven microfibers are shown in Figure 3. On PLLA, the rate of adherence of PC12 cells was approximately 3750/sample. Most of the adherent cells were non-neurites, and cells with long neurites were not observed. On PLLA/AG73, a similar number of adherent cells was observed, but neurite outgrowth was slightly enhanced in comparison to PLLA. PC12 cells have been reported to adhere to AG73-immobilized substrates through syndecans and the NGF pathway has been reported to be activated, resulting in neurite outgrowth (Suzuki et al., 2003b). Thus, AG73 must be stably immobilized on a substrate to express its biological function. The AG73 was removed from the surface of the PLLA/AG73 microfibers in culture medium, resulting in poor enhancement of adhesion and neurite outgrowth of PC12 cells. On PLLA/AG73(VPGIG) 30 microfibers, the adhesion and neurite outgrowth of PC12 cells was significantly accelerated compared to PLLA and PLLA/AG73. Because the hydrophobicity of the (VPGIG) 30 region renders $A G 73-(V P G I G)_{30}$ insoluble in PBS, it was stably bound to the PLLA. The hydrophilic AG73 region was available to contact PC12 cells at the outermost surface of the microfibers, resulting in promotion of adhesion and neurite outgrowth of PC12 cells.

\section{NERVE REGENERATION IN THE RABBIT MODEL OF NERVE INJURY}

The electrospun microfibrous conduits had a three-layered structure, including a PLLA/PEG outer layer, a PLLA middle layer, and a PLLA, PLLA/AG73, or PLLA/ AG73-(VPGIG) 30 inner layer, as shown in Figure 4. PEG was used in the outer layer to prevent the adhesion of surrounding tissues, because the adhesion of surrounding tissues to nerves causes painful traction 


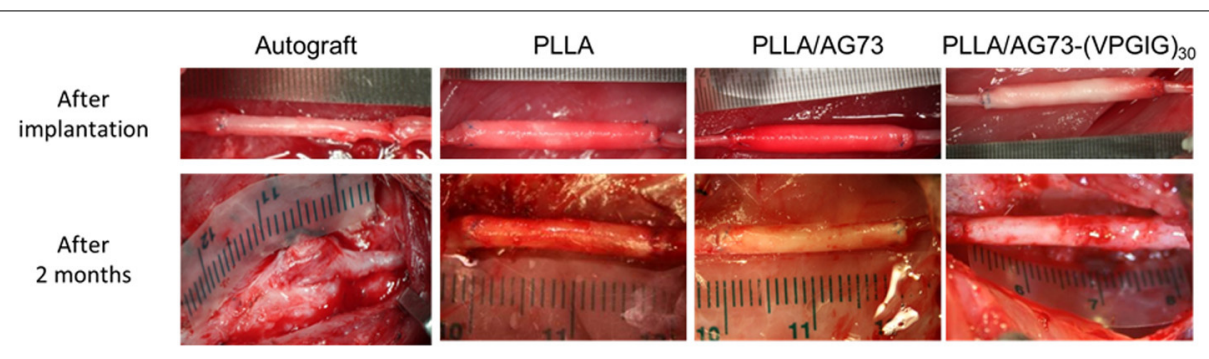

FIGURE 5 | Intraoperative photographs of autograft and micro-fibrous conduits (A) immediately after implantation and (B) 2 months after implantation. The proximal side is shown on the left.

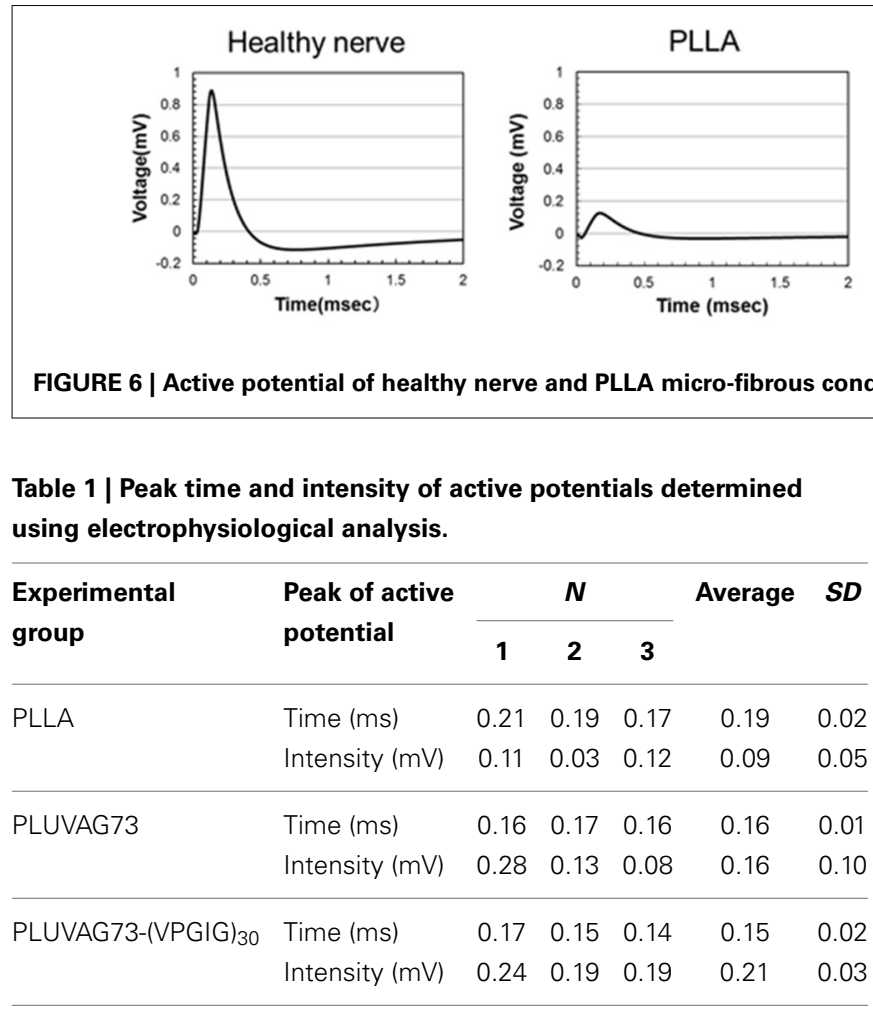

neuropathies (Tashiro et al., 1989). The microfibrous conduits were approximately $500-\mu \mathrm{m}$ thick, and the diameter of the PLLA/PEG microfiber outer layer was approximately $2.0 \mu \mathrm{m}$. Intraoperative photographs of the autografts and the microfibrous conduits in the rabbit tibial nerve gap were taken immediately after the implantation, and are shown in Figure 5. The conduits possessed sufficient strength for suturing and maintained their tubular shape after implantation. Two months after implantation, the nerve autografts were strongly adhered to the surrounding tissue and muscle, as shown in Figure 5. In contrast, the microfibrous conduits were easily located because the PEG in the PLLA microfibers of the outer layer had suppressed tissue adhesion. All conduits maintained their tubular structure during the 2 months, due to the slow degradation of the high molecular weight PLLA.

Reinnervation by nerve autografts or conduit implantation was analyzed by electrophysiological detection of active potentials
(Figure 6). The action potential of healthy tibial nerve was $0.9 \mathrm{mV}$ at $0.12 \mathrm{~ms}$. The intensity and peak time of the action potential are summarized in Table 1. No action potential was detected in implanted nerve autografts, due to the abnormal adhesion of surrounding tissues, but action potentials were reproducibly detected for PLLA microfibrous conduits. In unmodified PLLA conduit, the time and intensity of the action potential were $0.19 \mathrm{~ms}$ and $0.09 \mathrm{mV}$, respectively. Mixing the AG73 peptide in the inner layers lightly improved the action potential, to $0.16 \mathrm{mV}$ at $0.16 \mathrm{~ms}$. The microfibrous conduit with a PLLA/AG73-(VPGIG) 30 inner layer carried an action potential of $0.15 \mathrm{~ms}$ at $0.21 \mathrm{mV}$. This recovery is far from functional reinnervation, but nerve regeneration was slightly enhanced by mixing PLLA with AG73(VPGIG) ${ }_{30}$, compared to PLLA and PLLA/AG73 nerve conduits due to the stable interaction of AG73-(VPGIG) 30 with PLLA microfibers.

\section{CONCLUSION}

PLLA microfibers containing the AG73 peptide or the elastinlaminin mimetic protein AG73-(VPGIG) 30 were fabricated using an electrospinning procedure. AG73-(VPGIG) 30 was homogeneously mixed in PLLA microfibers, and the fibers were insoluble in a physiological environment. Neurite outgrowth of PC12 cells was promoted on the PLLA/AG73-(VPGIG) 30 non-woven microfibers compared to that on the PLLA and PLLA/AG73 nonwoven microfibers. In addition, we prepared electrospun microfibrous conduits with a three-layered structure: a PLLA/PEG outer layer, a PLLA middle layer, and a PLLA, PLLA/AG73, or PLLA/AG73-(VPGIG) 30 inner layer. When microfibrous conduits were implanted into a $2.0-\mathrm{cm}$ gap in an injured rabbit tibial nerve, their tubular structure was maintained after suturing. Although nerve autografts strongly adhered to the 
surrounding tissue, PLLA microfibrous conduits did not, owing to PEG mixed in the outer layer. The active potential was slightly improved in PLLA/AG73-(VPGIG) 30 microfibrous conduit compared to PLLA and PLLA/AG73 microfibrous conduits. However, this recovery was insufficient to achieve functional reinnervation. Microfiber orientation has been reported to influence the differentiation and proliferation of neural stem cell (Bashur et al., 2006; Ghasemi-Mobarakeh et al., 2008). In this study, the structure of the AG73-(VPGIG) 30 microfibers of the inner layer was random. Alignment of the inner-layer fibers of conduits is expected to enhance reinnervation. The results of this study demonstrate that the electrospun PLLA microfiber conduit with a PEG-mixed outer layer and an AG73-(VPGIG) $30^{-}$ mixed inner layershows excellent potential for enhancing nerve regeneration.

\section{ACKNOWLEDGMENTS}

This work was partially supported by a Grant-in-Aid from the Comprehensive Research on Disability Health and Welfare Program, the Ministry of Health, Labor and Welfare of Japan, the S-innovation Research Program for the "Development of the biofunctional materials for realization of innovative medicine," Japan Science and Technology Agent (JST), and Intramural Research Fund of National Cerebral and Cardiovascular Center.

\section{REFERENCES}

Ao, Q., Wang, A., Cao, W., Zhang, L., Kong, L., He, Q., et al. (2006). Manufacture of multimicrotubule chitosan nerve conduits with novel molds and characterization in vitro. J. Biomed. Mater. Res. A 77A, 11-18. doi: 10.1002/jbm.a. 30593

Archibald, S. J., Shefner, J., Krarup, C., and Madison, R. D. (1995). Monkey median nerve repaired by nerve graft or collagen nerve guide tube. J. Neurosci. 15, 4109-4123.

Bashur, C. A., Dahlgren, L. A., and Goldstein, A. S. (2006). Effect of fiber diameter and orientation on fibroblast morphology and proliferation on electrospun poly(D,L-lactic-co-glycolic acid) meshes. Biomaterials 27, 5681-5688. doi: 10.1016/j.biomaterials.2006.07.005

Chernousov, M. A., Yu, W., Chen, Z., Carey, D. J., and Strickland, S. (2008). Regulation of schwann cell function by the extracellular matrix. GLIA 56, 1498-1507. doi: 10.1002/glia.20740

Freier, T., Montenegro, R., Koh, H. S., and Shoichet, M. S. (2005). Chitin-based tubes for tissue engineering in the nervous system. Biomaterials 26, 4624-4632. doi: 10.1016/j.biomaterials.2004.11.040

Ghasemi-Mobarakeh, L., Prabhakaran, M. P., Morshed, M., Nasr-Esfahani, M.-H., and Ramakrishna, S. (2008). Electrospun poly( $\varepsilon$-caprolactone)/gelatin nanofibrous scaffolds for nerve tissue engineering. Biomaterials 29, 4532-4539. doi: 10.1016/j.biomaterials.2008.08.007

Hersel, U., Dahmen, C., and Kessler, H. (2003). RGD modified polymers: biomaterials for stimulated cell adhesion and beyond. Biomaterials 24, 4385-4415. doi: 10.1016/S0142-9612(03)00343-0

Huang, Z., Zhang, Y. Z., Kotaki, M., and Ramakrishna, S. (2003). A review on polymer nanofibers by electrospinning and their applications in nanocomposites. Compos. Sci. Technol. 63, 2223-2253. doi: 10.1016/S0266-3538(03) 00178-7

Ichihara, S., Inada, Y., and Nakamura, T. (2008). Artificial nerve tubes and their application for repair of peripheral nerve injury: an update of current concepts, ainjury. Injury 39(Suppl. 4), S29-S39. doi: 10.1016/j.injury.2008. 08.029

Iwamoto, Y., Robey, F. A., Graf, J., Sasaki, M., Kleinman, H. K., Yamada, Y., et al. (1987). YIGSR, a synthetic laminin pentapeptide, inhibits experimental metastasis formation. Science 238, 1132-1134. doi: 10.1126/science.29 61059
Kakinoki, S., Uchida, S., Ehashi, T., Murakami, A., and Yamaoka, T. (2011). Surface modification of poly(L-lactic acid) nanofiber with oligo(D-Lactic acid) bioactive-peptide conjugates for peripheral nerve regeneration. Polymers 3, 820-832. doi: 10.3390/polym3020820

Kakinoki, S., and Yamaoka, T. (2010). Stable modification of poly(lactic acid) surface with neurite outgrowth-promoting peptides via hydrophobic collagen-like sequence. Acta Biomater. 6, 1925-1930. doi: 10.1016/j.actbio.2009. 12.001

Kakinoki, S., and Yamaoka, T. (2014). Thermoresponsive elastin/laminin mimicking artificial protein for modifying PLLA scaffolds in nerve regeneration. J. Mat. Chem. B. doi: 10.1039/c4tb00305e

Lohmeyer, J. A., Siemers, F., Machens, H.-G., and Mailänder, P. (2009). The clinical use of artificial nerve conduits for digital nerve repair: a prospective cohort study and literature review. J. Reconstr. Microsurg. 25, 55-61. doi: 10.1055/s-0028-1103505

Lundborg, G., Dahlin, L. B., Danielsen, N., Gelberman, R. H., Longo, F. M., Powell, H. C., et al. (1982). Nerve regeneration in silicone chambers: influence of gap length and of distal stump components. Exp. Neurol. 76, 361-375. doi: 10.1016/0014-4886(82)90215-1

Lynn, S. K., Yannas, I. V., and Bonfield, W. (2004). Antigenicity and immunogenicity of collagen. J. Biomed. Mater. Res. 71B, 343-354. doi: 10.1002/jbm.b. 30096

Mainil-Varlet, P., Gogolewski, S., and Nieuwenhuis, P. (1996). Long-term soft tissue reaction to various polylactides and their in vivo degradation. J. Mater. Sci. Mater. Med. 7, 713-721. doi: 10.1007/BF00121406

Nakamura, T., Inada, Y., Fukuda, S., Yoshitani, M., Nakada, A., Itoi, S., et al. (2004). Experimental study on the regeneration of peripheral nerve gaps through a polyglycolic acid-collagen (PGA-collagen) tube. Brain Res. 1027, 18-29. doi: 10.1016/j.brainres.2004.08.040

Nomizu, M., Song, S. Y., Kuratomi, Y., Tanaka, M., Kim, W. H., Kleinman, H. K., et al. (1996). Active peptides from the carboxyl-terminal globular domain of laminin alpha2 and Drosophila alpha chains. FEBS Lett. 396, 37-42. doi: 10.1016/0014-5793(96)01060-5

Rao, S. S., and Winter, J. O. (2009). Adhesion molecule-modified biomaterials for neural tissue engineering. Front. Neuroeng. 2:6. doi: 10.3389/neuro.16.006.2009

Rutka, J. T., Apodaca, G., Stern, R., and Rosenblum, M. (1988). The extracellular matrix of the central and peripheral nervous systems: structure and function. J. Neurosurg. 69, 155-170. doi: 10.3171/jns.1988.69.2.0155

Sieminow, M., and Brzezicki, G. (2009). Current techniques and concepts in peripheral nerve repair. Int. Rev. Neurobiol. 87, 141-172. doi: 10.1016/S00747742(09)87008-6

Smit, X., van Neck, J. W., Afoke, A., and Hovius, S. E. R. (2004). Reduction of neural adhesions by biodegradable autocrosslinked hyaluronic acid gel after injury of peripheral nerves: an experimental study. J. Neurosurg. 101, 648-652. doi: 10.3171/jns.2004.101.4.0648

Suzuki, M., Itoh, S., Yamaguchi, I., Takakuda, K., Kobayashi, H., Shinomiya, K., et al. (2003a). Tendon chitosan tubes covalently coupled with synthesized laminin peptides facilitate nerve regeneration in vivo. J. Neurosci. Res. 72, 646-659. doi: 10.1002/jnr.10589

Suzuki, N., Ichikawa, N., Kasai, S., Yamada, M., Nishi, N., Morioka, H., et al. (2003b). Syndecan binding sites in the laminin $\alpha 1$ chain $\mathrm{G}$ domain. Biochemistry 42, 12625-12633. doi: 10.1021/bi030014s

Tashiro, K., Sephel, G. C., Weeks, B., Sasaki, M., Martin, G. R., Kleinman, H. K., et al. (1989). A synthetic peptide containing the IKVAV sequence from the a chain of laminin mediates cell attachment, migration, and neurite outgrowth. J. Biol. Chem. 264, 16174-16182.

Thomas, P. K. (1964). The deposition of collagen in relation to schwann cell basement membrane during peripheral nerve regeneration. J. Cell Biol. 23, 375-382. doi: $10.1083 /$ jcb.23.2.375

Toyota, B., Carbonetto, S., and David, S. (1990). A dual laminin/collagen receptor acts in peripheral nerve regeneration. Proc. Natl. Acad. Sci. U.S.A. 87, 1319-1322. doi: 10.1073/pnas.87.4.1319

Wang, K.-K., Nemeth, I. R., Seckel, B. R., Chakalis-Haley, D. P., Swann, D. A., Kuo, J.-W., et al. (1998). Hyaluronic acid enhances peripheral nerve regeneration in vivo. Microsurgery 18, 270-275.

Yoshitani, M., Fukuda, S., Itoi, S., Morino, S., Tao, H., Nakada, A., et al. (2007). Experimental repair of phrenic nerve using a polyglycolic acid and collagen tube. J. Thorac. Cardiovasc. Surg. 133, 726-732. doi: 10.1016/j.jtcvs.2006. 08.089 
Conflict of Interest Statement: The authors declare that the research was conducted in the absence of any commercial or financial relationships that could be construed as a potential conflict of interest.

Received: 19 May 2014; accepted: 26 June 2014; published online: 18 July 2014.

Citation: Kakinoki S, Nakayama M, Moritan T and Yamaoka T (2014) Three-layer microfibrous peripheral nerve guide conduit composed of elastin-laminin mimetic artificial protein and poly(L-lactic acid). Front. Chem. 2:52. doi: 10.3389/fchem. 2014.00052
This article was submitted to Chemical Biology, a section of the journal Frontiers in Chemistry.

Copyright (c) 2014 Kakinoki, Nakayama, Moritan and Yamaoka. This is an openaccess article distributed under the terms of the Creative Commons Attribution License (CC BY). The use, distribution or reproduction in other forums is permitted, provided the original author(s) or licensor are credited and that the original publication in this journal is cited, in accordance with accepted academic practice. No use, distribution or reproduction is permitted which does not comply with these terms. 